\title{
Is atmospheric carbon dioxide removal a game changer for climate change mitigation?
}

\author{
Elmar Kriegler • Ottmar Edenhofer • Lena Reuster • \\ Gunnar Luderer • David Klein
}

Received: 4 May 2012 / Accepted: 23 December 2012 /Published online: 22 February 2013

(C) The Author(s) 2013. This article is published with open access at Springerlink.com

\begin{abstract}
The ability to directly remove carbon dioxide from the atmosphere allows the decoupling of emissions and emissions control in space and time. We ask the question whether this unique feature of carbon dioxide removal technologies fundamentally alters the dynamics of climate mitigation pathways. The analysis is performed in the coupled energyeconomy-climate model ReMIND using the bioenergy with CCS route as an application of CDR technology. BECCS is arguably the least cost CDR option if biomass availability is not a strongly limiting factor. We compare mitigation pathways with and without BECCS to explore the impact of CDR technologies on the mitigation portfolio. Effects are most pronounced for stringent climate policies where BECCS is a key technology for the effectiveness of carbon pricing policies. The decoupling of emissions and emissions control allows prolonging the use of fossil fuels in sectors that are difficult to decarbonize, particularly in the transport sector. It also balances the distribution of mitigation costs across future generations. CDR is not a silver bullet technology. The largest part of emissions reductions continues to be provided by direct mitigation measures at the emissions source. The value of CDR lies in its flexibility to alleviate the most costly constraints on mitigating emissions.
\end{abstract}

\section{Introduction}

Climate change is an extraordinary policy challenge. The atmosphere-ocean system integrates the greenhouse gas emissions from every place and every sector of human society, and mediates the impacts of climate change globally. Emissions reductions today will have a long lead time until the accumulation of carbon dioxide in the atmosphere is stopped and

Electronic supplementary material The online version of this article (doi:10.1007/s10584-012-0681-4) contains supplementary material, which is available to authorized users.

This article is part of a Special Issue on "Carbon Dioxide Removal from the Atmosphere: Complementary Insights from Science and Modeling” edited by Massimo Tavoni, Robert Socolow, and Carlo Carraro.

E. Kriegler $(\bowtie) \cdot$ O. Edenhofer $\cdot$ L. Reuster $\cdot$ G. Luderer $\cdot$ D. Klein

Potsdam Institute for Climate Impact Research (PIK), Potsdam, Germany

e-mail: kriegler@pik-potsdam.de

URL: www.pik-potsdam.de 
eventually reversed. Seen through this lens, the deck is stacked against climate change mitigation. Carbon dioxide emissions propagate through time and space, but their reduction can only occur at the time and location of the emissions themselves. This makes technologies attractive that would allow the compensation of carbon dioxide emissions by directly extracting it from the atmosphere-ocean system. Such carbon dioxide removal (CDR) technologies are receiving increasing attention (Keith 2009; Lackner 2010; The Royal Society 2009). CDR technologies can be used to compensate historic emissions at a later point in time, and distributed emissions, e.g. from the transport sector, at a single point in space. CDR technologies could therefore alter climate mitigation strategies dramatically, if they became economically viable (Keith et al. 2005).

This article will explore the sensitivity of mitigation pathways to the possibility of decoupling emissions reductions in space and time by means of CDR in greater depth. Key questions are how the intertemporal and cross-sectoral profile of emissions reductions is changed, and what implications result for the inter-generational distribution of mitigation costs.

Direct carbon dioxide removal (CDR) from the atmosphere-ocean system can be achieved with the application of several technologies. First, there are land-based removal methods such as afforestation, land use management, and biomass combustion to produce electricity or fuel coupled with sequestering the $\mathrm{CO}_{2}$ in geological formations. This method known as bio-energy with carbon capture and storage (abbreviated as BECCS) yields a net removal of carbon dioxide from the atmosphere. Another biological but ocean-based method is iron fertilization, which has been reviewed critically on the grounds of its uncertain effectiveness and environmental side effects (The Royal Society 2009).

There exist also chemical approaches to CDR. One is the terrestrial process of reacting $\mathrm{CO}_{2}$ with minerals to form carbonates and thereby consume $\mathrm{CO}_{2}$ (The Royal Society 2009). Another is direct carbon dioxide capture from ambient air (DAC) by using solvents like sodium hydroxide (Lackner 2010; Stolaroff et al. 2008). Although the costs of this technology are still high it could play an important role for long-term climate policy (Keith et al. 2005; Keith 2009). Some authors argue that the cost of large-scale air capture will eventually decrease and become competitive in the long run. Recent publications, however, argue that air capture costs have been underestimated and competitiveness with mitigation technologies is unlikely to be reached even in the long run (House et al. 2011; Schellnhuber 2011).

All CDR technologies described here share the need for available and safe $\mathrm{CO}_{2}$ storage. Approaches like BECCS and direct air capture require geological storage space and consume energy for the capture and sequestration of the $\mathrm{CO}_{2}$ (The Royal Society 2009). The availability of underground storage space is exacerbated by the competition with carbon capture and storage (CCS) at fossil fuel fired power plants and public opposition to new projects in spatial proximity.

Integrated assessment models (IAMs) are an adequate tool to explore the role of CDR for mitigation pathways as they cover the relevant dynamics regarding technologies, the energy system, and the economic system (Clarke et al. 2009; Edenhofer et al. 2010; Luderer et al. 2012a, b). IAMs have been used to analyze the role of BECCS for stringent mitigation strategies aiming, e.g., to stabilize at $450 \mathrm{ppm} \mathrm{CO} 2$ equivalent concentration. These studies have shown that BECCS plays a crucial role by contributing negative emissions to the overall emissions budget (Azar et al. 2010; IPCC 2011; Tavoni and Tol 2010; van Vuuren et al. 2010).

Our analysis supports the finding from these studies that BECCS is a key technology for mitigating climate change, and in particular for reaching stringent climate stabilization goals. These findings are not specific to BECCS, but emerge from the general characteristics of CDR technologies, i.e. the ability to decouple emissions and emissions control in space and time (Keith et al. 2005). We provide a detailed exploration of the combined intertemporal, sectoral and technological implications of CDR using the example of BECCS. BECCS helps to balance the 
mitigation costs between generations by alleviating the pressure, particularly in the 2 nd half of the century, on sectors like the transport sector that are hardest to decarbonize. At the same time, we show that CDR is not a silver bullet dominating the mitigation portfolio. There is a large amount of low to medium cost mitigation options that will be tapped independently of the availability of CDR.

A specific characteristic of BECCS is its reliance on biomass. Large scale use of bioenergy can have adverse impacts on land use and biodiversity, including the potential of substantial greenhouse gas emissions from bioenergy production and land conversion (IPCC 2011). Such effects have been accounted for to varying degrees in integrated assessments (Creutzig et al. 2012a, b; Popp et al. 2011; Wise et al. 2009). Assessments of the BECCS potential can be overly optimistic, if the associated land use dynamics is neglected. Our analysis does not include an explicit land use model, but constrains the magnitude of bioenergy use motivated by the assumption that it is restricted to abandoned or unused agricultural land.

The subsequent discussion is structured into three sections. Section 2 introduces the methods used for the analysis, in particular the integrated assessment model ReMIND and the set of scenarios that were investigated. Section 3 is dedicated to the results on the use of BECCS in the climate policies scenarios, and its effect on the distribution of the mitigation effort over time, technologies and sectors. Section 4 concludes the paper and provides suggestions for further research.

\section{Methods}

The analysis is based on outputs from the global Integrated Assessment Model ReMIND (Refined Model of Investment and Technological Development) in its version 1.3 (Edenhofer et al. 2010; Leimbach et al. 2010; Luderer et al. 2011; Luderer et al. 2012a, b). The model represents 11 world regions and considers a time horizon from 2005 to 2100. It consists of three modules: a macro-economic Ramsey-type optimal growth module, a detailed energy-system module, and a climate module. Energy end use is split into three categories: Stationary electric and non-electric energy use in a compound industry, residential and commercial sector, and energy use in the transportation sector. The secondary energy carriers electricity, hydrogen, gases, solids, liquids, and heat are provided to these end use types. The model version used for the analysis here limits transport energy to liquid fuels and hydrogen and does not account for the electrification of transport. The model includes a detailed representation of primary to secondary energy conversion technologies. Among them are four bioenergy conversion routes that can be combined with CCS: BioIGCC plants for the production of electricity, biomass to liquid production, and biomass to hydrogen conversion for use in the residential \& commercial and in the transport sector. The technologies involve different techno-economic parameters and capture rates for the CCS process which affect their deployment (mix) (see supplementary Table S1). The capture rate is particularly important in situations of stringent mitigation action. The share of the four BECCS technologies in the overall use of bioenergy becomes very large ( $80 \%$ to $94 \%$ ) in the second half of the century across all climate policy scenarios (see below). It reaches $54 \%-76 \%$ already in 2030 even though the additional deployment of CCS has extra costs. Hence, the increase in bioenergy demand can be primarily attributed to a strong demand for negative emissions.

Emissions of $\mathrm{CO}_{2}, \mathrm{SO}_{2}$ and carbonaceous aerosols resulting from the combustion of fossil fuels are represented by source in REMIND. An $\mathrm{N}_{2} \mathrm{O}$ emissions factor is applied to bioenergy use. $\mathrm{CH}_{4}$ and $\mathrm{N}_{2} \mathrm{O}$ emission reduction potentials in the energy and land use sectors, and the $\mathrm{CO}_{2}$ reduction potential from reducing tropical deforestation are represented via marginal abatement cost curves. Afforestation, a competing CDR option, is not included in the model. 
Nine scenarios were explored with the ReMIND model for the purpose of this analysis (see Table S1). They are based on scenarios specified within the Asian Modeling Exercise (Calvin et al. 2012; Luderer et al. 2012a, b). We consider two types of climate mitigation scenarios: The stabilization scenarios meet a $450 \mathrm{ppm} \mathrm{CO} 2 \mathrm{e}$ target, i.e. a limit of total anthropogenic forcing to $2.6 \mathrm{~W} / \mathrm{m}^{2}$ by 2100 (Scenario label: $450 \mathrm{ppm}$ ). Temporary overshooting of the forcing target is allowed. In the tax scenarios, we assumed a globally uniform carbon equivalent price starting in 2015 and increasing at a rate of $5 \% /$ year, with price levels of $10 \$ / \mathrm{tCO} 2 \mathrm{e}, 30 \$ /$ tCO2e, and $50 \$ / \mathrm{tCO} 2 \mathrm{e}$ in 2020 , corresponding to roughly $500 \$ / \mathrm{tCO} 2 \mathrm{e}, 1,500 \$ / \mathrm{tCO} 2 \mathrm{e}$ and 2,500 \$/tCO2e in 2100 (Scenario labels: \$10 Tax, \$30 Tax, \$50 Tax). The model implementation of the stabilization target and the tax scenarios are detailed in supplementary Table S2. Only $\mathrm{CO}_{2}, \mathrm{CH}_{4}$ and $\mathrm{N}_{2} \mathrm{O}$ emissions are subjected to emission pricing in the stabilization and tax scenarios. The idealized setting of the mitigation scenarios represents a policy situation where full flexibility in pursuing the most efficient mitigation action across regions and sectors is assured. It provides a useful benchmark for the analysis of least cost mitigation strategies. This analysis explores the role of CDR for climate policy by comparing scenarios with and without the availability of BECCS (Scenario label: No BECCS).

Although BECCS constitutes an example of CDR technologies, there are some features like the production of energy and the use of biomass that distinguishes it from other CDR technologies such as DAC. We therefore need to assess how BECCS-specific characteristics impact our conclusions on the role of CDR as a technology class. A limiting factor for the deployment of BECCS is bioenergy supply. We assumed a non-linearly increasing cost function for primary bioenergy production with an upper bound of $200 \mathrm{EJ}$ per year (based on Hoogwijk 2004; see Fig. S1). The constraint is used as a proxy for limiting the land competition between food and energy crops. Hoogwijk (2004) estimated 177-438 EJ of bioenergy potential on abandoned and unused land in 2050 across a range of socio-economic scenarios. The recent IPCC Special Report on renewable energy estimated between 100 and $300 \mathrm{EJ} / \mathrm{yr}$ of sustainable bioenergy production in 2050 (Chum et al. 2011). Bioenergy prices will strongly increase with the scale of bioenergy use due to a supply constraint reflecting limited availability of suitable land and sustainability considerations.

To put the deployment of BECCS into the context of overall CDR approaches, we relate the price of sequestering a ton of carbon dioxide via BECCS in the ReMIND model to the costs of DAC (Fig. 1). An indication for the storage costs at the margin is given by the carbon price as a function of BECCS deployment. Cost estimates for DAC vary on a range

Fig. 1 Carbon price plotted against $\mathrm{CO} 2$ removal via BECCS in ReMIND. The carbon price accrues as revenue for the removal of 1 ton of $\mathrm{CO} 2$. It is the dominant factor of BECCS revenues (which include the sale of energy) for prices above $\$ 100$ per tCO2e and therefore a useful proxy for the marginal cost of carbon dioxide removal via BECCS. This is compared with cost estimates for direct air capture technologies

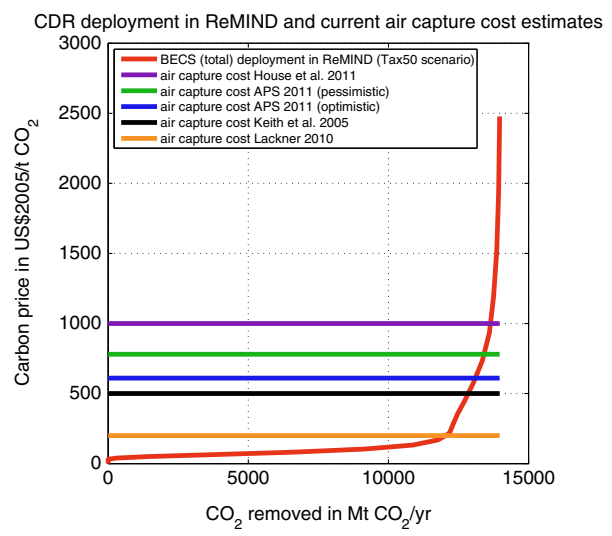


of US\$200 to US\$1,000 per ton of removed carbon dioxide (House et al. 2011; Keith et al. 2005; Lackner 2010; Socolow et al. 2011). The marginal costs of BECCS are lower than the most optimistic DAC cost estimate up to the removal of $12 \mathrm{GtCO} 2 \mathrm{e}$ per year and then increase rapidly due to bioenergy supply limitations. Processing $200 \mathrm{EJ}$ of biomass generates approx. $18 \mathrm{GtCO} 2$ which amounts to $13.5-16.5 \mathrm{GtCO} 2$ of stored carbon for capture rates ranging between 75 and $90 \%$. At this magnitude, BECCS costs are governed by the biomass price with large rents accruing to bioenergy producers. These specific BECCS characteristics need to be kept in mind for the interpretation of our results. Due to its comparatively low initial costs, BECCS will be deployed much earlier than DAC technologies and due to bioenergy supply limitations it will be outcompeted by DAC at removal levels above 13-14 GtCO2e per year. This shows that DAC may be an attractive option for the 2 nd half of the 21 st century if costs are in the range of current estimates. The assessment is, of course, sensitive to the assumed capture rates for BECCS and the bioenergy supply cost curves.

Finally, we note that ReMIND assumes upper bounds on regional geological CO2 storage capacities that sum to a global $\mathrm{CO}_{2}$ storage potential of $3,670 \mathrm{GtCO}_{2}$. The injection rate into geological formations is capped at $0.5 \% / y r$ of the regional storage potential mimicking geological, technical, and institutional limitations on the rate at which geological reservoirs can be filled. This flow constraint leads to an upper bound of $18 \mathrm{GtCO}_{2} /$ year on CCS deployment. It is globally binding for the stringent $\$ 50$ tax and $450 \mathrm{ppm}$ CO2e scenarios. This induces a trade-off between $\mathrm{CCS}$ at fossil fuel power plants and BECCS. In addition, ReMIND considers adjustment costs for all technologies including BECCS. They penalize rapid capacity expansion by adding a markup to investment costs as a function of the relative increase in deployment.

\section{Results}

\subsection{Effect of CDR on emissions and mitigation costs}

All climate policies lead to substantial emissions reductions relative to reference emissions (Fig. 2) indicating the large mitigation potential in the energy system particularly from reducing the use of coal (see Fig. S5). The reference scenario represents a world without climate policy, where emissions from fossil fuel combustion increase substantially until 2060 , followed by a

a

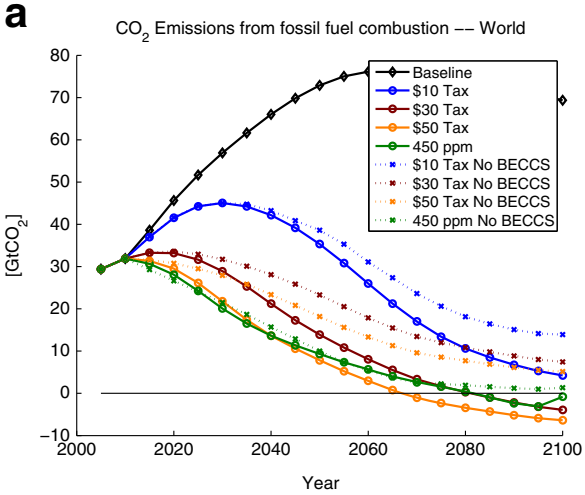

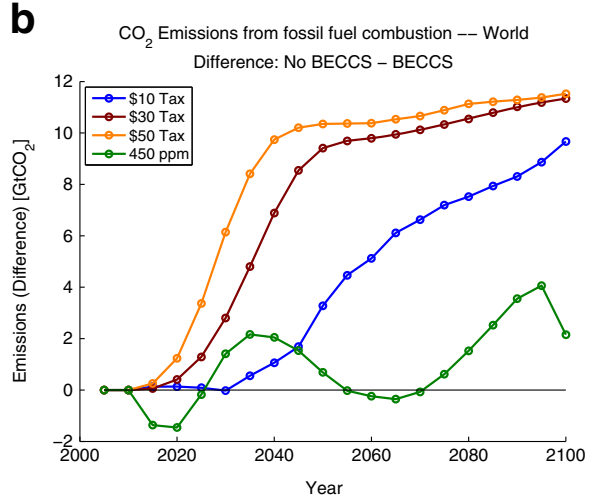

Fig. $2 \mathrm{CO} 2$ emissions from the energy system and industry net of CDR for the $\$ 10, \$ 30, \$ 50$ tax, and the $450 \mathrm{ppm}$ stabilization scenarios (left panel), and difference in emissions profiles with and without BECCS (Emissions without BECCS minus emissions with BECCS; right panel) 
decline thereafter. This is due to increasing fossil fuel prices with cumulative extraction, and decreasing costs of learning technologies such as wind and solar power, so that renewable energies become competitive at the end of the century even without carbon pricing.

The additional gain in emissions reductions from strengthening the carbon tax scenarios diminishes as a result of the non-linear increase of marginal abatement costs in the energy sector. Achieving the $450 \mathrm{ppm} \mathrm{CO} 2 \mathrm{e}$ stabilization target requires the strongest near term emissions reductions given the long lifetime of $\mathrm{CO} 2$ in the atmosphere ${ }^{1}$.

The availability of CDR in the three tax scenarios leads to lower emissions and slower diminishing returns from an increase of the carbon tax. This shows the additional flexibility that BECCS adds to the portfolio of mitigation options in the energy sector. The situation is markedly different for a climate stabilization target $(450 \mathrm{ppm})$ which largely determines the cumulative emissions budget. It leads to cumulated Kyoto gas emissions of 2000-2100 $\mathrm{GtCO}_{2} \mathrm{e}$ for the period 2005-2100. The CO2 emissions trajectories with and without BECCS diverge from each other after 2070. In the absence of BECCS, higher reductions in $\mathrm{CH} 4$ and $\mathrm{N} 2 \mathrm{O}$ emissions partly compensate for the higher long-term CO2 emissions (cf. van Vuuren and Riahi 2011). Cumulative CO2 emissions from 2005-2100 amount to 1,160 GtCO2, about $8 \%$ higher than in the case with BECCS. The difference in $\mathrm{CO} 2$ emissions between the two cases shows that higher long term emissions are also compensated by lower short term emissions in the absence of BECCS. The additional up and down of the emissions difference in the intermediate period is due to a switch in the use of BECCS technologies, in particular the phasing in and out of BioIGCCs with CCS during 2020-2060 (see Fig. 6). We note that this particular result is sensitive to the consideration of BECCS technologies and their capture rates.

The variation of the mitigation costs across the tax and $450 \mathrm{ppm}$ scenarios shows a reverse image of the emissions results (Fig. 3). In the tax scenarios, the availability of the BECCS option results in higher mitigation costs, because at a given carbon price greater emission reductions are performed. The situation is substantially different for the $450 \mathrm{ppm}$ stabilization target. The mitigation costs more than double without BECCS. The doubling arises from strongly increasing mitigation costs for generations in the more distant future. Costs for the period 2070-2090 quadruple without carbon dioxide removal. If BECCS is not available, very costly mitigation options need to be tapped in the 2 nd half of the 21 st century to achieve near zero emissions in order to stay below the climate target (see next section). Thus, the flexibility provided by CDR eases the high costs for future generations and balances the inter-generational distribution of costs in the $450 \mathrm{ppm}$ scenario.

\subsection{Effect of CDR on sectoral mitigation efforts}

The availability of CDR has significant implications for the mitigation effort in different end use sectors (Fig. 4). As mentioned above, a small carbon price signal already brings large emissions reductions in all sectors, indicating a range of low cost mitigation options unrelated to CDR. The magnitude of the effect is to a certain extent baseline dependent, and is dominated by the large coal use in the REMIND reference scenario.

The electricity sector reacts most strongly to the increasing carbon price until midcentury, while the transportation sector is hardest to decarbonize beyond the utilization of low cost options, particularly in the short to mid-term. This can also be seen when switching off BECCS. Transport emissions in the tax cases are markedly higher. For the $450 \mathrm{ppm}$ case,

\footnotetext{
${ }^{1}$ The upturn in emissions at the end of the century is due to the formulation of the target as an overshoot target. The downward trend in forcing does not need to be continued in 2100 leading to a relaxation of the mitigation effort.
} 
Fig. 3 Generational mitigation costs (consumption loss) as percentage of consumption in the reference case for different time periods (NPV at $5 \%$ discount rate)

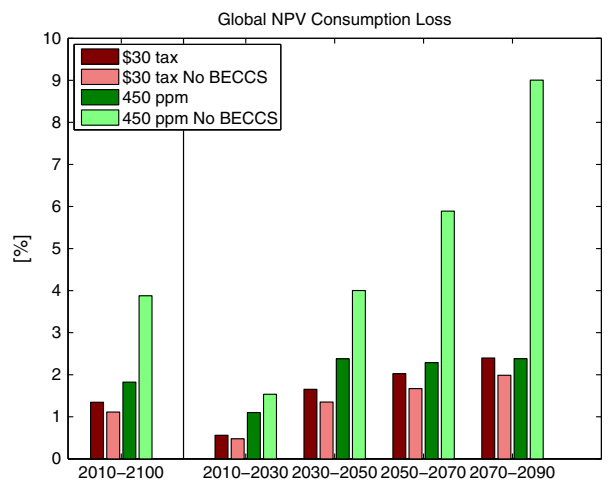

transport emissions are reduced by relying on transport demand reductions and non-BECCS technologies at significantly higher costs. Negative emissions in the transport and nonelectric stationary sector are obtained from the use of hydrogen produced from biomass with CCS. Additional negative emissions in the transport sector are generated by liquefaction of biomass with CCS. While the electricity sector carries the bulk of near to midterm emissions reductions with BECCS, its reductions are much more gradual in the absence of BECCS and

a

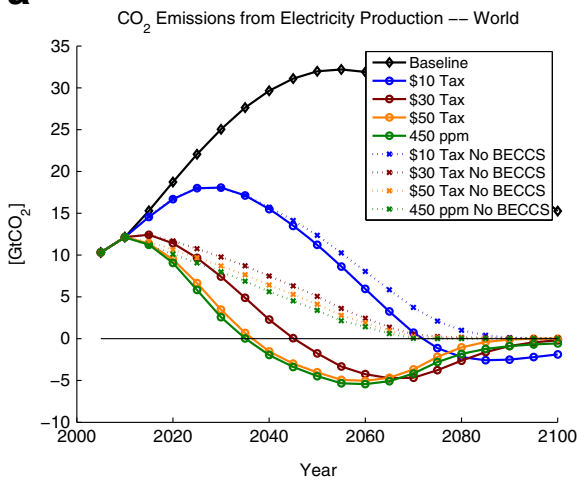

b

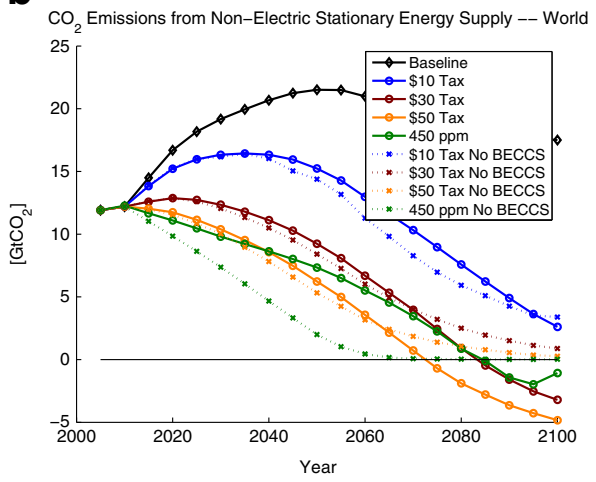

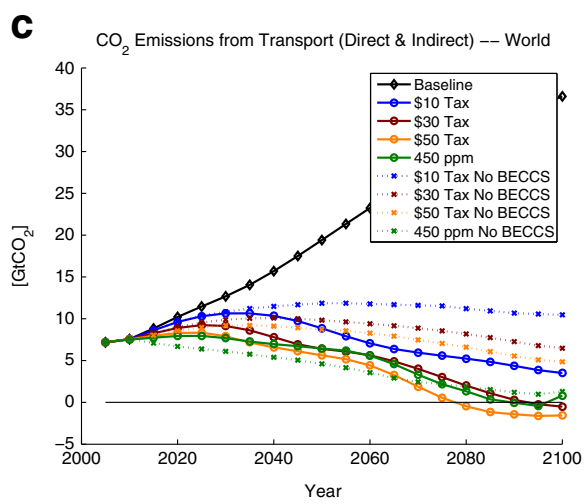

Fig. 4 Sectoral emissions with and without BECCS: From a electric and $\mathbf{b}$ non-electric energy use in the stationary (industry, residential and commercial) sector, and from $\mathbf{c}$ the transport sector 
do no longer increase with increasing carbon prices beyond a $\$ 30$ tax path. This indicates that the lifetime of existing fossil fuel infrastructure limits the emissions reductions in this sector (the model does not allow for early retirement).

Figure 5 analyses the breakdown of emissions reductions on individual sectors and BECCS. It can be seen that BECCS is not dominating the mitigation portfolio (the larger part is direct sector mitigation), but plays a crucial role in adjusting the mitigation requirements on sectors to increase efficiency. A comparison of the cases with and without BECCS reveals that BECCS is used to compensate emissions from the stationary non-electric and transport sectors. In the absence of BECCS, a larger amount of near to mid-term emissions reductions comes from non-electric energy use in the industry, residential and commercial sectors. In the $450 \mathrm{ppm} \mathrm{CO2e} \mathrm{scenario} \mathrm{where} \mathrm{the} \mathrm{mitigation} \mathrm{effort} \mathrm{cannot} \mathrm{be} \mathrm{relaxed} \mathrm{due} \mathrm{to}$ the absence of BECCS, the transport sector also has to carry a larger mitigation effort. The additional burden on the transport sector, much of which realized through the reduction of transport energy demand ( $45 \%$ w.r.t. the case with BECCS and even $65 \%$ w.r.t. to the
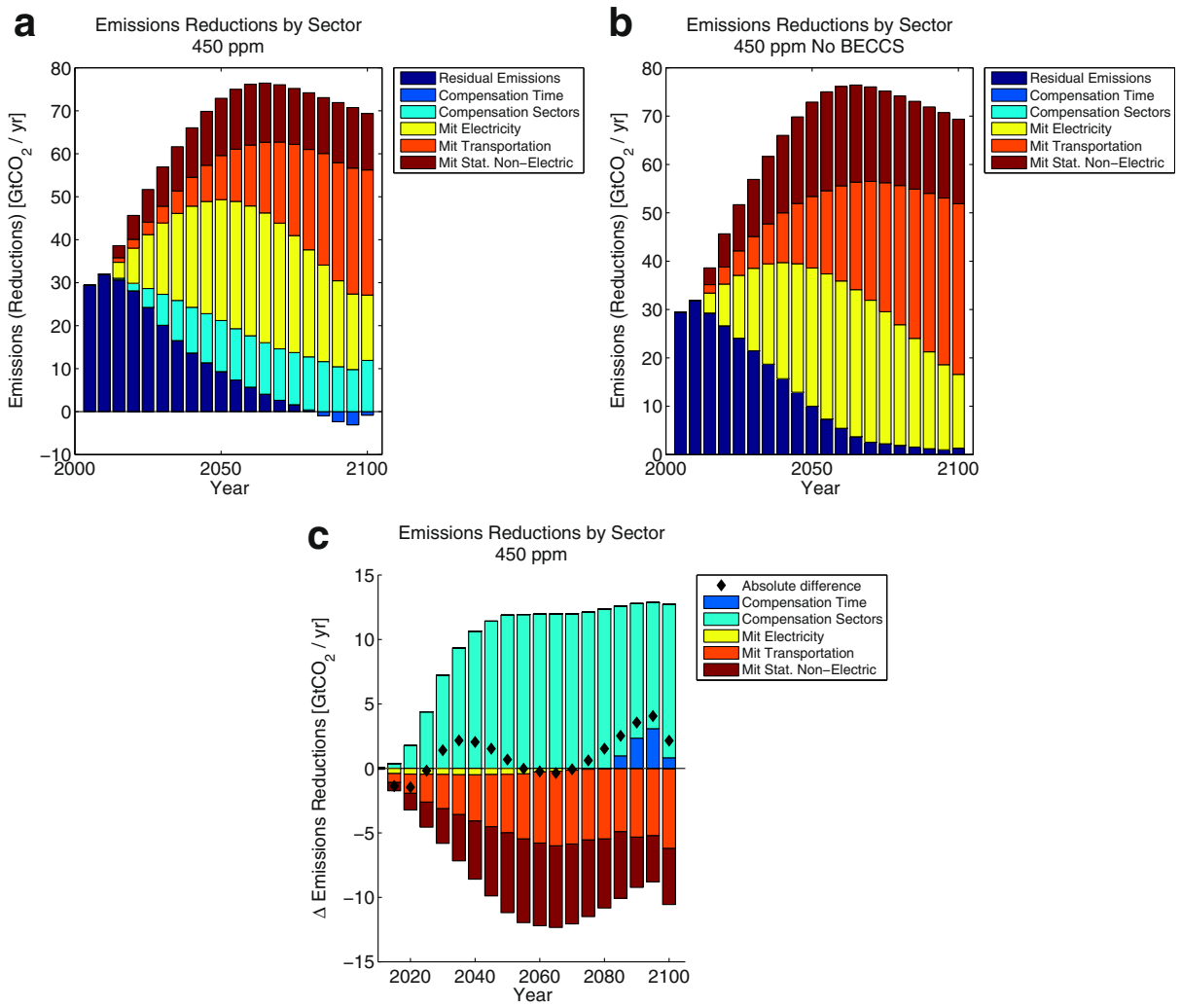

Fig. 5 Breakdown of emissions reductions into direct sector mitigation (abbreviated "Mit" in the legend) from the stationary electric, stationary non-electric, and transport sectors, and carbon dioxide removal via BECCS (separated into compensation of sectoral emissions at a given point in time and compensation over time from net negative emissions). Shown are the emissions reductions for the $450 \mathrm{ppm}$ CO2e stabilization scenario with BECCS (upper left panel) and without BECCS (upper right panel), and the difference between the two cases (BECCS-No BECCS; lower panel). See supplementary Figs. S3 and S4 for the results for the tax scenarios 
reference case), is the main driver for the high cost increases in the long run. We note, however, that electrification of transport is another significant option to reduce emissions from the transport sector which can reduce the need for BECCS to compensate transport emissions. This option is not modeled in the present analysis, although factor substitution of non-electric energy with electricity is accounted for.

\subsection{Effect of BECCS on the technology portfolio}

The availability of BECCS has a profound impact on the energy technology portfolio in the climate policy scenarios. BECCS is utilized in all climate policy scenarios reaching a similar share of ca. $22 \%$ of primary energy supply in 2100 . There is only a slow expansion of BECCS in the low tax scenario, but high carbon price signals in the short term lead to rapid expansion. The primary energy share of BECCS increases from $5 \%$ in 2020 to $16 \%$ in 2030 by roughly $80 \mathrm{EJ}$ in the $450 \mathrm{ppm} \mathrm{CO} 2 \mathrm{e}$ scenario.

The mix of deployed BECCS technologies strongly depends on the stringency of mitigation policy (Fig. 6). The two BECCS technologies with the highest capture rates (BioIGCC and hydrogen production) dominate the use of bioenergy in the $\$ 30$ and $\$ 50$ tax cases and the 450 ppm CO2e scenario. The ReMIND model shows a distinct shift from
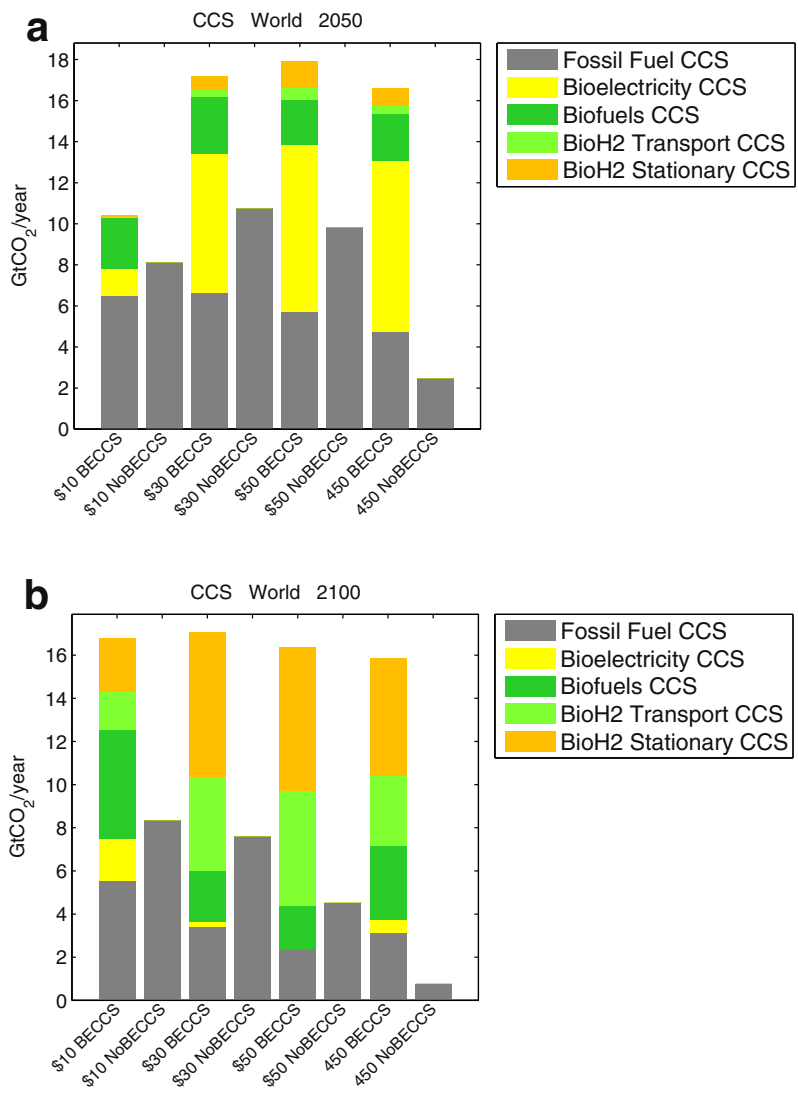

Fig. 6 CCS use by technology in the years 2050 (left panel) and 2100 (right panel) for the eight policy scenarios considered in this study 
BioIGCC to Bio-hydrogen production in the second half of the century due to the use of the hydrogen in sectors that are more difficult to decarbonize than the electricity sector, and because of the slightly higher capture rate ( $90 \%$ in $\mathrm{B} 2 \mathrm{H} 2$ vs $80 \%$ in BioIGCC). In the case of carbon tax policies, BECCS displaces some of the CCS at fossil fuel power plants due to the trade-off induced by the flow constraint on annual sequestration. The opposite result is obtained for imposing a stringent climate stabilization target. Deployment of fossil fuel CCS increases significantly if BECCS is available. This result depends partly on our assumption that up to $10 \%$ of the oxidized carbon in fossil fuel power plants is not captured, but released to the atmosphere (see Table S1). The residual emissions from fossil fuel use with CCS are large enough to make this option unattractive under a $450 \mathrm{ppm} \mathrm{CO} 2 \mathrm{e}$ target without BECCS. This result would no longer be valid, if the capture rate of CCS was increased over time to eliminate residual emissions. More generally, the availability of BECCS helps to prolong the use of fossil fuels in the energy sector, which also makes fossil fuel CCS more attractive.

In all climate policy cases, biomass use is somewhat larger if BECCS is available, but remains significant in the absence of BECCS. Without BECCS, biomass is used primarily for the production of biofuels instead of electricity (Fig. S5, left panel). The reduction of bioelectricity in the absence of BECCS (Fig. S5, right panel) is mostly compensated by other renewable power, while nuclear power does not expand significantly beyond its utilization in the reference scenario due to a uranium constraint. In the carbon tax cases, compensation is also provided by an increased deployment of fossil fuel combustion with CCS. The situation is markedly different in the $450 \mathrm{ppm}$ CO2e scenario. In the absence of BECCS, the electricity sector not only has to compensate the re-direction of bioenergy, but also the reduction of fossil fuel CCS. The sector responds by a large increase in the deployment of solar energy, which pushes up costs.

\section{Conclusions}

Our analysis supports the finding that carbon dioxide removal from the atmosphere is an important option for mitigating climate change. This finding is also supported by earlier assessments of the role of CDR (Keith et al. 2005) or more specifically BECCS (Azar et al. 2010; D. van Vuuren et al. 2010) for climate policy. We have added to these studies a detailed exploration of the combined intertemporal and sectoral implications of CDR using the example of BECCS, and a discussion of the impact on BECCS on the energy technology portfolio.

CDR is deployed in all climate policy scenarios that we investigated. It is primarily used to compensate for emissions from the transport sector as well as emissions from non-electric energy use in the industry, residential, and commercial sectors. While the availability of BECCS increases the amount of emission reductions from carbon taxes at similar levels of mitigation costs, it significantly reduces the mitigation costs to reach ambitious stabilization targets. A key result of our study is that CDR balances the intergenerational distribution of mitigation costs of climate stabilization that otherwise would rise rapidly towards the end of the century. The substantial cost increases arise from two factors: a much stronger reduction of energy use in the transportation sector and a much larger deployment of solar energy in the electricity sector, which substitutes some of the non-electric use and replaces fossil CCS and bioelectricity. The limited bioenergy is now primarily used for biofuel production.

Despite the key role of CDR for climate mitigation, it is not a silver bullet. Our results show that the largest part of emissions reductions comes from direct mitigation measures. BECCS is only a (smaller) part of the mitigation portfolio in all climate policy scenarios. However, due to its ability to compensate past and distant emissions it is deployed strategically to alleviate the most costly mitigation constraints. 
Although we have focused on the generic aspects of BECCS as a CDR technology, we have highlighted areas where specific BECCS characteristics play a role. These are in particular its use for energy production in addition to CDR, and constraints due to limited biomass supply. The energy aspect is marginalized by the ability of BECCS to remove carbon dioxide from the atmosphere. If bioenergy supply is limited, those BECCS technologies with highest capture rates outcompete biofuel production on the grounds of their higher CDR capability (van Vuuren et al. 2010). The bioenergy supply limitations lead to strongly increasing costs of BECCS at deployment levels close to the constraint spanning the entire range of cost estimates for direct air capture. At smaller deployment levels, BECCS outcompetes even the most optimistic cost estimates for DAC, underlining its attractiveness as CDR option.

An important concern with BECCS is its dependence on large scale bioenergy use and its impact on land use. Adverse effects can include competition with food production, reduction of biodiversity, additional emissions due to increased fertilizer use and land use change emissions from, e.g., forest conversion (IPCC 2011). Although there is large uncertainty about sustainable levels of bioenergy use (Creutzig et al. 2012a, b), it can be expected that sustainability constraints will limit the use of BECCS as CDR technology. In our analysis, BECCS deployment is effectively limited to a removal of $14-15 \mathrm{GtCO}_{2}$ per year. If CDR is to be employed at very large scale, BECCS very likely would need to be complemented by other technologies such as DAC that do not suffer from bioenergy constraints. As a caveat, these results strongly depend on the choice of bioenergy supply potential and the lack of alternatives to decarbonize the transport sector. A sensitivity study of different supply potentials and the consideration of electric transport should be a topic for future research.

We conclude that CDR can be a game changer for climate policy in the sense that it significantly improves feasibility and cost considerations for achieving stringent climate stabilization. It is, however, a complement, not a substitute to the traditional approach of mitigating emissions at their source. Given the potential significance of CDR, it will be important to further investigate its viability and economics. Key questions are the sustainability of BECCS given land use limitations on bioenergy, the role direct air capture can play as an alternative to BECCS, the viability of geological sequestration of $\mathrm{CO}_{2}$ at large scale, in particular with regard to permanence of storage and public acceptability, the potential embedding of CDR in a carbon capture and cycling economy (Möller 2011; Zeman and Keith 2008), and the trade-offs with alternative options for decarbonizing energy use such as energy storage and electrification (Kriegler 2011). Finally, the value of CDR may be further enhanced in situations of uncertainty about climate damages and mitigation technologies (Keith et al. 2005). It therefore will be important to further investigate the role of CDR for mitigating climate change in the context of risk analysis.

Open Access This article is distributed under the terms of the Creative Commons Attribution License which permits any use, distribution, and reproduction in any medium, provided the original author(s) and the source are credited.

\section{References}

Azar C, Lindgren K, Obersteiner M, Riahi K, Vuuren DP, Elzen KMGJ, Möllersten K et al (2010) The feasibility of low $\mathrm{CO} 2$ concentration targets and the role of bio-energy with carbon capture and storage (BECCS). Clim Chang 100(1):195-202. doi:10.1007/s10584-010-9832-7

Calvin K, Clarke L, Krey V, Blanford G, Jiang K, Kainuma M, Kriegler E, Luderer G, Shukla PR (2012) The role of Asia in mitigating climate change: results from the Asia modeling exercise. Energ Econ 34(suppl 3):S251S260. doi:10.1016/j.eneco.2012.09.003 
Chum H, Faaij A, Moreira J, Berndes G, Dhamija P, Dong H, Gabrielle B, Goss Eng A, Lucht W, Mapako M, Masera Cerutti O, McIntyre T, Minowa T, Pingoud K (2011) Bioenergy. In: Edenhofer O, Pichs-Madruga R, Sokona Y, Seyboth K, Matschoss P, Kadner S, Zwickel T, Eickemeier P, Hansen G, Schlomer S, von Stechow C (eds) IPCC special report on renewable energy sources and climate change mitigation. Cambridge University Press, Cambridge and New York

Clarke L, Edmonds J, Krey V, Richels R, Rose S, Tavoni M (2009) International climate policy architectures: overview of the EMF 22 international scenarios. Energ Econ 31:S64-S81. doi:10.1016/j.eneco.2009.10.013

Creutzig F, Popp A, Plevin R, Luderer G, Minx J, Edenhofer O (2012a) Reconciling top-down and bottom-up modelling on future bioenergy deployment. Nature Climate Change 2:320-327. doi:10.1038/ nclimate 1416

Creutzig F, Stechow CV, Klein D, Hunsberger C, Bauer N, Popp A, Edenhofer O (2012b) Can bioenergy assessments deliver? Economics of Energy \& Environmental Policy 1(2):65-82

Edenhofer O, Knopf B, Barker T, Baumstark L, Bellevrat E, Chateau B, Criqui P et al (2010) The economics of low stabilization: model comparison of mitigation. Energ J 31(Special Issue 1):11-48

Hoogwijk MM (2004) On the global and regional potential of renewable energy. Utrecht University, Utrecht, p 256

House KZ, Baclig AC, Ranjan M, van Nierop E, Wilcox J, Herzog HJ (2011) Economic and energetic analysis of capturing CO2 from ambient air. Proc Natl Acad Sci U S A 108(51):20428-20433. doi:10.1073/ pnas. 1012253108

IPCC (2011) In: Edenhofer O, Pichs-Madruga R, Sokona Y, Seyboth K, Matschoss P, Kadner S, Zwickel T et al (eds) IPCC special report on renewable energy sources and climate change mitigation. Cambridge University Press, Cambridge and New York, p 1075

Keith DW (2009) Why capture CO2 from the atmosphere? Science (New York, NY) 325(5948):1654-1655. doi:10.1126/science. 1175680

Keith DW, Ha-Duong M, Stolaroff JK (2005) Climate strategy with Co2 capture from the air. Clim Chang 74 (1-3):17-45. doi:10.1007/s10584-005-9026-x

Kriegler E (2011) Comment on the status and prospects of renewable energy for combating global warming. Energ Econ 33(4 Special Issue):594-596

Lackner K (2010) Washing carbon out of the air. Sci Am 302:66-71

Leimbach M, Bauer N, Baumstark L, Edenhofer O (2010) Mitigation costs in a globalized world: climate policy analysis with REMIND-R. Environ Model Assess 15:155-173

Luderer G, Bosetti V, Jakob M, Leimbach M, Steckel JC, Waisman H, Edenhofer O (2012a) The economics of decarbonizing the energy system - results and insights from the RECIPE model intercomparison. Climatic Change 114:9-37. doi:10.1007/s10584-011-0105-x

Luderer G, Pietzcker RC, Kriegler E, Haller M, Bauer N (2012b) Asia's role in mitigating climate change : a technology and sector specific analysis with ReMIND - R. Energ Econ 34(suppl 3):S378-S390

Luderer G, Leimbach M, Bauer N, Kriegler E (2011) Description of the ReMIND-R model. Potsdam Institute for Climate Impact Research. Retrieved from http:/www.pik-potsdam.de/research/sustainable-solutions/ models/remind/REMIND Description.pdf

Möller D (2011) SONNE: solar-based man-made carbon cycle and the carbon dioxide economy. Ambio. doi:10.1007/s13280-011-0197-6

Popp A, Dietrich JP, Lotze-Campen H, Klein D, Bauer N, Krause M, Beringer T et al (2011) The economic potential of bioenergy for climate change mitigation with special attention given to implications for the land system. Environ Res Lett 6(3):034017. doi:10.1088/1748-9326/6/3/034017

Schellnhuber HJ (2011) Geoengineering: the good, the MAD, and the sensible. Proc Natl Acad Sci U S A 108 (51):20277-20278. doi:10.1073/pnas.1115966108

Socolow R, Desmond M, Aines R, Blackstock J, Bolland O, Kaarsberg T, Lewis N, et al. (2011) Direct air capture of CO 2 with chemicals. American Physical Society (APS). Retrieved from http://www.aps.org/ policy/reports/assessments/upload/dac2011.pdf

Stolaroff JK, Keith DW, Lowry GV (2008) Carbon dioxide capture from atmospheric air using sodium hydroxide spray. Environ Sci Technol 42:2728-2735

Tavoni M, Tol RSJ (2010) Counting only the hits? The risk of underestimating the costs of stringent climate policy. Clim Chang 100(3-4):769-778. doi:10.1007/s10584-010-9867-9

The Royal Society (2009) Geoengineering the climate. Design. The Royal Society, London, p 82, Retrieved from http://royalsociety.org/uploadedFiles/Royal_Society_Content/policy/publications/2009/8693.pdf

van Vuuren DP, Riahi K (2011) The relationship between short-term emissions and long-term concentration targets. Clim Chang 104(3-4):793-801

van Vuuren D, Bellevrat E, Kitous A, Isaac M (2010) Bio-energy use and low stabilization scenarios. Energ J 31(Special Issue 1):193-222 
Wise M, Calvin K, Thomson A, Clarke L, Bond-Lamberty B, Sands R, Smith SJ et al (2009) Implications of limiting CO2 concentrations for land use and energy. Science (New York, NY) 324(5931):1183-1186. doi:10.1126/science. 1168475

Zeman FS, Keith DW (2008) Carbon neutral hydrocarbons. Phil Trans Roy Soc A 366(1882):3901-3918. doi:10.1098/rsta.2008.0143 